\title{
No further increase in asthma, hay fever and atopic sensitisation in adolescents living in Switzerland
}

\author{
C. Braun-Fahrländer*, M. Gassner ${ }^{\#}$, L. Grize*, K. Takken-Sahli ${ }^{\uparrow}$, U. Neu ${ }^{+}$, T. Stricker ${ }^{\S}$, H.S. Varonier ${ }^{f}$, \\ B. Wüthrich**, F.H. Sennhauser ${ }^{\S}$, and the Swiss Study on Childhood Allergy and Respiratory symptoms \\ with respect to Air Pollution (SCARPOL) team
}

No further increase in asthma, hay fever and atopic sensitisation in adolescents living in Switzerland. C. Braun-Fahrländer, M. Gassner, L. Grize, K. Takken-Sahli, U. Neu, T. Stricker, H.S. Varonier, B. Wüthrich, F.H. Sennhauser, and the Swiss Study on Childhood Allergy and Respiratory symptoms with respect to Air Pollution (SCARPOL) team. C) ERS Journals Ltd 2004.

ABSTRACT: Prevalence rates of childhood asthma and allergy have been on the increase for several decades. The present study investigated whether this trend continued during the 1990s in adolescents living in Switzerland.

Between 1992 and 2000, the change in prevalence of specific immunoglobulin $\mathbf{E}$ to aeroallergens, asthma symptoms and hay fever symptoms assessed by parents' and students' answers to the International Study of Asthma and Allergies in Childhood questions was investigated using three cross-sectional surveys. In total 1,324 (74.9\%), $1,668(80.6 \%)$ and $1,250(73.9 \%)$ adolescents participated.

Prevalence rates of asthma and current asthmatic symptoms remained constant, irrespective of whether the assessment was based on parental questionnaires or the student's self-completed written or video questionnaires (students' report of current wheeze 8.8, 7.3, and 8.3\%). Similarly, no further increase was observed for reported hay fever rates and allergic sensitisation rates (positive multiscreen allergy test, SX1-test: 34.6, 38.9, and 35.6\%, respectively). Although time trends in the occurrence of a series of known risk factors were recorded, none of these factors had a significant impact on asthma and allergy prevalence over time.

No further increase in asthma and allergy rates occurred during the 1990s in adolescents living in Switzerland. However, to adequately assess the trend a longer period of observation is needed.

Eur Respir J 2004; 23: 407-413.
*Institute of Social and Preventive Medicine, University of Basel, Basel, "School Health Service, Grabs, "School Health Service, Zurich, ${ }^{+}$Institute of Geography, University of Bern,

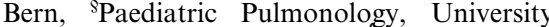
Children's Hospital, Zurich, Allergy Clinic, Paediatric University Hospital, Geneva, and **Allergy Unit, Dept of Dermatology, University Hospital, Zurich, Switzerland.

Correspondence: C. Braun-Fahrländer, Institute of Social and Preventive Medicine, University of Basel, Steinengraben 49, CH-4051

Basel, Switzerland.

Fax: 41612702225

E-mail: C.Braun@unibas.ch

Keywords: Allergy, asthma, children, time-trend

Received: June 302003

Accepted after revision: September 282003

The study was supported by grants from the Swiss National Science Foundation (Grant 4026-033109), the Swiss Federal Office of Public Health, the Swiss Federal Office of the Environment, the Lung Association of Zurich and St. Gallen, and the cantonal health services of Zurich, St. Gallen, Valais, Vaud, Geneva and Bern.
Over recent decades, a large number of epidemiological studies investigating the change in prevalence of childhood asthma and allergies using the same methodology and examining the same population showed an increase in the occurrence of the disease [1-4]. Although individual studies may be criticised because of methodological limitations [5], the consistency of the results of $>20$ studies reporting an asthma increase of $\sim 5 \%$ per annum over the period of observation argues for a true change in prevalence [6]. Concomitant to the rise in asthma prevalence, an even stronger increase in the prevalence of hay fever has been reported in England and Scotland [2, 7], Australia [3], and Sweden [8]. In Switzerland, hay fever prevalence in adults has been on the rise since the 1920s [9]. In adolescents, two surveys $10 \mathrm{yrs}$ apart demonstrated an increase in asthma prevalence [4] and GASSNER et al. [10] gave evidence for rising prevalence rates of hay fever in a small sample of Swiss adolescents monitored yearly between 1983 and 1992. This increase in hay fever was paralleled by an increase in sensitisation rates to common inhalant allergens. However, the evidence from more recent

For editorial comments see page 359. studies conducted during the 1990s is more conflicting. An Italian study of schoolchildren [11] reported no further increase in physician-diagnosed asthma and parent-reported attacks of breathlessness between 1992 and 1998. However, two recent studies in preschoolchildren [12] and primary schoolchildren [13] showed a strong continuing growth in the prevalence of asthma during the 1990s.

Many environmental factors have been hypothesised to contribute to the increasing asthma and atopy rates including both indoor [14] and ambient air pollution [15], reduced exposure to microbial stimulation [16] and changes in diet [17]. However, the observed increase has not convincingly been explained by any of these factors and there is limited evidence of changes in exposure to these risk factors over time.

The present study (Swiss Study on Childhood Allergy and Respiratory symptoms with respect to Air Pollution (SCARPOL)) [18] was set up in 1992 to monitor the development of asthma and allergy rates over time in Swiss adolescents attending school in Switzerland by investigating the same age group of children with the same methodology every 3 yrs. In addition to including the written and video questionnaires of 
the International Study of Asthma and Allergies in Childhood (ISAAC), a range of environmental exposures were repeatedly assessed and specific immunoglobulin E (IgE) levels were determined in each of the three cross-sectional surveys. The goal of the study was to examine whether between 1992 and 1999 the frequency of asthma, hay fever and allergic sensitisation increased among 14-yr-old adolescents in Switzerland.

\section{Methods}

\section{Study organisation and participation rate}

SCARPOL is a multicentre surveillance study designed to investigate the time trend of asthma and allergies in schoolchildren. It is organised within the framework of the school health services, which includes a routine visit during school grade 8 at aged 13-14 yrs. The surveillance study consists of repeated cross-sectional surveys of the same agegroup of children living in four urban centres (Bern, Biel, Lugano and Zurich) and in four rural communities (Grabs, Langnau, Montana and Payerne) in Switzerland. In the urban centres, a representative sample of schools was invited to participate in the surveillance study. In the small rural communities, all children of the respective age group were invited to participate.

Parents were asked to fill in a detailed questionnaire on respiratory and allergic diseases and on risk factors for these diseases. The core questions on asthma and allergy in ISAAC were incorporated in the questionnaire [19]. In total, $74.9 \%$ $(1324 / 1768)$ of the parents filled in the questionnaire during the school year 1992-1993, 80.6\% (1668/2070) in 1995-1997 and $73.9 \%(1250 / 1692)$ in $1999-2000$. In each of the three surveys, Swiss parents were significantly more likely to participate than non-Swiss parents and participating children were on average 6 months younger than nonparticipants.

In addition, students of consenting parents were asked to fill in the ISAAC student's written questionnaire on asthma and to answer the video questionnaire in class. A parent's and a student's completed written questionnaire were available for $65.5 \%$ (1158/1768), 66.9\% (1386/2070) and 69.9\% (1182/1692) of the students, respectively. A parents' completed written questionnaire and a student's completed video questionnaire were also available for $64.5 \%$ (1156/1768), 68.4\% (1415/2070) and $67.7 \%$ (1145/1692) of the students, respectively. With the exception of student's current smoking, all risk factors were assessed by parental questionnaire.

Students and parents were further asked to consent to blood sampling for specific IgE determination. Among the students with a parents' completed questionnaire, 56.2\% (743/ $1323), 60.0 \%(831 / 1384)$ and $49.7 \%$ (587/1182) agreed. In all three surveys, students participating in blood sampling were more likely to have a family history of atopy, to suffer of hay fever and asthma and to be of Swiss nationality. No other differences were observed.

The study protocol was approved by the ethics committees of the Universities of Geneva and Bern. Parents consented to the study by completing the parental questionnaire and by giving written consent for blood sampling in their children.

\section{Questionnaires}

Altogether, five responses relating to asthma symptoms and diagnosis obtained from the written parental and students' ISAAC questionnaires were considered: wheeze and asthma ever, wheeze during the last year, wheeze during exercise, and speech impairment by wheeze. In addition, two responses relating to hay fever symptoms and diagnosis obtained from the parental questionnaire were analysed: sneezing attack without a cold accompanied by itchy and watery eyes during the past year, and a diagnosis of hay fever.

Three sequences of the video questionnaire showing young people with overt signs of asthma were used for analyses: 1) moderate wheeze at rest (ever or during the past year); 2) wheeze and shortness of breath after exercise (during past year); and 3) a severe attack of asthma with wheezing and breathlessness at rest (during past year).

\section{Serological test}

Blood samples $(10 \mathrm{~mL})$ were taken and the serum separated by spinning for $10 \mathrm{~min}$ at $1000 \times g$. The samples were kept frozen and sent to the allergy laboratory of the Dept of Dermatology in Zurich. The mutiscreen test, SX1, a fluoroenzyme immunoassay testing for eight common inhalative allergens (Pharmacia and Upjohn, Uppsala, Sweden) was performed with all serum samples by CAP-fluoroenzyme immunoassay (FEIA) technology (Pharmacia and Upjohn) [20]. If the SX1 test was positive, the specific IgE levels to six allergens (timothy grass, birch, mugwort, house dust mite, cat and dog dander) were determined by CAP-FEIA. The cut-off for a positive result was defined as a specific IgE concentration $\geqslant 0.69 \mathrm{KU} \cdot \mathrm{L}^{-1}(\mathrm{CAP}$ class $\geqslant 2)$.

\section{Serological tests in Grabs since 1983}

In one of the rural study areas (Grabs), one of the coauthors of the present study (M. Gassner) had started a serosurveillance programme in 1983 [10, 21]. This included a blood sample of all consenting 8th graders sent to the laboratory in Zurich for analysis as described above. In addition, the occurrence of hay fever was assessed by questionnaire. In 1992-1993 M. Gassner joined the SCARPOL project but continued the sero-surveillance programme in Grabs on a yearly basis. Between 1983 and 2002 a total of 1,587 students were invited to participate in the serosurveillance study (repeated cross-sectional sample of 848 th graders per year on average) and 1,296 students consented to blood sampling (average participation rate $81.7 \%$ ).

\section{Statistical analyses}

Prevalence of a series of risk factors and potential confounders were determined for each of the three surveys and the time trend assessed with the Cochran-Armitage test for trend. Crude and adjusted prevalence for asthma and wheeze were calculated according to parental reports, and student's written and video answers. As the participation rate for serological testing was rather low, symptom rates were additionally calculated for the subsample of students with $\mathrm{IgE}$ measurements to evaluate the effect of potential selection bias.

Similarly, prevalence for hay fever and hay fever symptoms and for sensitisation were computed. A Generalised estimating equations model [22] was used to adjust symptom prevalence for known risk factors and potential confounders and to calculate the time trend. The final models contained all covariates that were either associated with health outcome or significantly changed over time.

To assess whether a family history of asthma and hay fever might modify the time-trend for asthma and hay fever, the multivariate regression models were separately run for the subsamples of students with and without a family history. 
Table 1.-Characteristics of study population and prevalence of risk factors in three consecutive surveys

\begin{tabular}{|c|c|c|c|c|}
\hline Characteristic/risk factor & $1992-1993$ & 1995-1997 & 1999-2000 & $\mathrm{p}$-value for trend \\
\hline Study participation & $1324(74.9)$ & $1668(80.6)$ & $1250(73.9)$ & 0.2761 \\
\hline Male sex & $630(47.6)$ & $837(50.2)$ & 609 (48.7) & 0.6211 \\
\hline Swiss nationality & 1029 (77.7) & $1250(75.4)$ & $938(75.5)$ & 0.2654 \\
\hline Urban residency & $851(64.3)$ & $1070(64.2)$ & $824(65.9)$ & 0.3306 \\
\hline Low parental education & $856(67.2)$ & $993(61.8)$ & $701(58.9)$ & $<0.0001$ \\
\hline Parental farming & $105(7.9)$ & $93(5.6)$ & $81(6.5)$ & 0.2892 \\
\hline Mother's history of asthma & $58(4.4)$ & $88(5.3)$ & $73(5.8)$ & 0.1113 \\
\hline Father's history of asthma & $79(6.0)$ & $86(5.2)$ & $77(6.2)$ & 0.6596 \\
\hline Mother's history of hay fever & $144(10.9)$ & $181(10.8)$ & $180(14.4)$ & 0.0024 \\
\hline Father's history of hay fever & $130(9.8)$ & $192(11.5)$ & $152(12.2)$ & 0.0809 \\
\hline Breastfeeding & $951(73.37)$ & $1332(80.9)$ & $1001(84.2)$ & $<0.0001$ \\
\hline No siblings & $165(12.7)$ & $206(12.4)$ & $131(10.6)$ & 0.0768 \\
\hline ETS exposure by mother & $308(23.3)$ & $399(24.4)$ & $303(25.9)$ & 0.1316 \\
\hline Student current smoker & $92(7.0)$ & $218(13.1)$ & $182(14.6)$ & $<0.0001$ \\
\hline Single oven heating with wood/coal & $132(10.0)$ & $244(14.7)$ & $175(14)$ & 0.0123 \\
\hline Water spots or mildew & $313(23.6)$ & $362(21.7)$ & $287(23.00)$ & 0.8607 \\
\hline Carpets in student's bedroom & $1038(79.2)$ & $1201(72.7)$ & $764(61.9)$ & $<0.0001$ \\
\hline Any pets & $833(62.9)$ & $1006(60.3)$ & $725(58.0)$ & 0.0132 \\
\hline Pets in student's bedroom & $447(36.5)$ & $548(34.5)$ & 403 (33.6) & 0.1621 \\
\hline Removed carpets due to allergy & $39(3.0)$ & $65(4.0)$ & $73(5.9)$ & 0.0002 \\
\hline Removed pets due to allergy & $34(2.6)$ & $28(1.7)$ & $31(2.5)$ & 0.845 \\
\hline Mother filled in questionnaire & $1108(84)$ & $1409(84.9)$ & $1034(83.2)$ & 0.4408 \\
\hline $\begin{array}{l}\text { Parents perceive air pollution as a risk } \\
\text { factor for respiratory disease in child }\end{array}$ & $166(13.3)$ & $188(11.9)$ & $136(11.6)$ & 0.2316 \\
\hline
\end{tabular}

Data are presented as n (\%) unless otherwise stated. ETS: environmental tobacco smoke.

Finally, for the subsample of Grabs, the yearly sensitisation rate was calculated and plotted versus the study year. SCARPOL sensitisation rates to the plot were then added, excluding the students from Grabs.

\section{Results}

Students were aged $14.0 \pm 0.71$ (mean \pm SD) yrs, $14.1 \pm 0.70$ yrs, and $13.9 \pm 0.70 \mathrm{yrs}$ in the three consecutive surveys, respectively, and were on average born in 1978 (1977-1979), 1981 (1980-1982) and 1985 (1984-1986). The characteristics of the study population and the prevalence of risk factors in the three surveys are given in table 1 .
The prevalence of asthma symptoms and asthma diagnosis in the three consecutive surveys was calculated according to parental reports and students answers to the ISAAC written and video questionnaires. As the number of students consenting to blood sampling was rather low, the symptom prevalence based on parental reports was also computed for the subsample of students with IgE measurements. Table 2 gives the crude and adjusted prevalence of asthma and related symptoms assessed by parental and students' written questionnaires. Adjusted prevalence rates and 95\% confidence intervals of wheeze during past year based on students' answers to the video questionnaire in the three consecutive surveys were $3.5 \%(2.6-4.8 \%), 3.8 \%(2.9-5.0 \%)$ and $4.5 \%$ (3.3-6.1\%), respectively, with a p-value for time trend of

Table 2. - Crude and adjusted prevalence of asthma symptoms and asthma diagnosis in three consecutive surveys according to parental reports and students answers to the ISAAC written questionnaire

\begin{tabular}{|c|c|c|c|c|c|c|c|}
\hline \multirow[t]{2}{*}{ Health outcome } & \multicolumn{2}{|r|}{ 1992-1993 } & \multicolumn{2}{|c|}{ 1995-1997 } & \multicolumn{2}{|c|}{ 1999-2000 } & \multirow[t]{2}{*}{$\mathrm{p}$-value for trend } \\
\hline & Crude & Adjusted & Crude & Adjusted & Crude & Adjusted & \\
\hline Parental questionnaire $\mathrm{n}$ & 1324 & & 1668 & & 1250 & & \\
\hline Wheeze ever & 20.9 & $19.9(17.6-22.4)$ & 20.7 & $19.5(17.4-21.7)$ & 25.2 & $22.5(20.0-25.2)$ & 0.14 \\
\hline Wheeze past year & 6.7 & $5.1(4.0-6.6)$ & 6.8 & $5.0(4.0-6.2)$ & 5.7 & $4.0(0.3-5.2)$ & 0.15 \\
\hline Wheeze after exercise & 9.1 & $7.8(6.4-9.4)$ & 8.6 & $6.8(5.6-8.2)$ & 8.3 & $7.4(6.0-9.1)$ & 0.78 \\
\hline Speech limiting wheeze & 1.4 & $0.9(0.5-1.7)$ & 1.2 & $0.7(0.4-1.2)$ & 1.4 & $0.7(0.4-1.2)$ & 0.37 \\
\hline Asthma ever & 9.7 & $7.8(6.4-9.5)$ & 10.7 & $7.6(6.4-9.1)$ & 10.3 & $7.4(6.0-9.1)$ & 0.74 \\
\hline Students' written questionnaire $\mathrm{n}$ & & 1158 & & 1386 & & 1182 & \\
\hline Wheeze ever & 18.5 & $17.8(15.4-20.4)$ & 17.6 & $16.1(14.0-18.3)$ & 20.4 & $16.6(14.4-19.0)$ & 0.55 \\
\hline Wheeze past year & 9.7 & $8.8(7.2-10.8)$ & 9.2 & $7.3(6.0-8.8)$ & 10.9 & $8.3(6.8-10.1)$ & 0.83 \\
\hline Wheeze after exercise & 18.9 & $19.3(16.8-22.0)$ & 15.2 & $13.5(11.5-15.6)$ & 18.5 & $16.8(14.5-19.2)$ & 0.29 \\
\hline Speech limiting wheeze & 2.2 & $1.5(1.0-2.5)$ & 1.9 & $1.3(0.8-2.0)$ & 2.4 & $1.6(1.0-2.6)$ & 0.75 \\
\hline Asthma ever & 10.8 & $9.6(7.9-11.7)$ & 10.1 & $8.7(7.2-10.5)$ & 12.3 & $9.6(7.9-11.5)$ & 0.98 \\
\hline
\end{tabular}

Data are presented as \% or \% (95\% confidence interval) unless otherwise stated. Symptom rates were adjusted for study year, sex, parental education, study area, maternal and paternal asthma and hay fever, breastfeeding, number of siblings, heating system, carpets in student's bedroom, pet ownership, getting rid of carpets because of the child's allergy, students active smoking, mother filling in the questionnaire and parental perception of air pollution as a risk factor for their child's respiratory health. 
Table 3.-Crude and adjusted prevalence of rhinitis symptoms, hay fever and sensitisation rates in three consecutive surveys, total sample and subsample with serologic measurements

\begin{tabular}{|c|c|c|c|c|c|c|c|}
\hline \multirow[t]{2}{*}{ Health outcome } & \multicolumn{2}{|c|}{$1992-1993$} & \multicolumn{2}{|c|}{$1995-1997$} & \multicolumn{2}{|c|}{$1999-2000$} & \multirow{2}{*}{$\begin{array}{l}\mathrm{p} \text {-value } \\
\text { for trend }\end{array}$} \\
\hline & Crude & Adjusted & Crude & Adjusted & Crude & Adjusted & \\
\hline Total sample parental questionnaire $n$ & 1324 & & 1668 & & 1250 & & \\
\hline $\begin{array}{l}\text { Sneezing attack without cold and itchy } \\
\text { watery eyes last year }\end{array}$ & 15.1 & $13.2(11.1-15.3)$ & 12.1 & $10.3(8.8-12.0)$ & 13.4 & $11.5(7.9-13.5)$ & 0.26 \\
\hline Hay fever & 17.8 & $16.5(14.4-18.8)$ & 15.7 & $13.9(12.1-15.8)$ & 18.8 & $16.1(13.9-18.4)$ & 0.89 \\
\hline Subsample with IgE measurements $n$ & 743 & & 831 & & 587 & & \\
\hline $\begin{array}{l}\text { Sneezing attack without cold and itchy } \\
\text { watery eyes last year }\end{array}$ & 17.2 & $13.9(11.4-16.8)$ & 13.8 & $11.3(9.2-13.8)$ & 16.0 & $15.1(12.1-18.6)$ & 0.60 \\
\hline Hay fever & 19.8 & $17.1(14.3-20.2)$ & 18.1 & $15.6(13.0-18.5)$ & 19.6 & $18.3(14.8-22.0)$ & 0.63 \\
\hline SX1 CAP class $\geqslant 2$ & 35.5 & $34.6(30.8-38.4)$ & 37.8 & $38.9(35.2-42.6)$ & 36.8 & $35.6(31.3-40.0)$ & 0.77 \\
\hline Outdoor allergens CAP class $\geqslant 2$ & 31.2 & $30.6(27.0-34.3)$ & 31.4 & $31.9(28.5-35.5)$ & 28.3 & $27.4(23.5-31.5)$ & 0.26 \\
\hline Indoor allergens CAP class $\geqslant 2$ & 21.8 & $19.8(16.8-23.1)$ & 24.2 & $24.1(21.0-27.5)$ & 21.6 & $19.9(16.5-23.6)$ & 0.96 \\
\hline
\end{tabular}

Data are presented as $\%$ or $\%$ (95\% confidence interval) unless otherwise stated. Symptom rates were adjusted for study year, sex, parental education, study area, maternal and paternal asthma and hay fever, breastfeeding, number of siblings, heating system, carpets in student's bedroom, pet ownership, getting rid of carpets because of the child's allergy, students active smoking, mother filling in the questionnaire and parental perception of air pollution as a risk factor for their child's respiratory health. IgE: immunoglobulin E.

0.62. Asthma symptom prevalence and asthma diagnosis rates remained stable over time independent of the type of questionnaire or the person reporting the symptoms. Time patterns were similar for crude and adjusted prevalence rates. Although agreement between parental and student's answers to the written and video questionnaires were moderate to low (kappa coefficient ranging between $0.72-0.38$ for the written questionnaires, and between $0.32-0.20$ for the video questionnaire) and parental reports of current wheeze and exercise wheeze were considerably lower than student's self-reported rates, the time trend of symptom prevalence was similar in all three questionnaires.

When the analyses were restricted to children of Swiss nationality the time trend was the same as in the larger sample. Adjusted prevalence rates of wheeze during the past year based on parental reports of Swiss children in the three surveys were $4.7 \%(3.5-6.2 \%), 5.2 \%(4.0-6.7 \%)$ and $3.8 \%$ $(2.7-5.2 \%)$, respectively, with a p-value for time trend of 0.27 .

Table 3 shows the crude and adjusted prevalence rates for hay fever symptoms and hay fever diagnosis based on parental reports, and the rates of sensitisation to any allergen
(SX1-test), to outdoor and indoor allergens. No clear time trend could be observed. As more children with a family history of asthma or hay fever accepted blood sampling, the time trend of symptom prevalence rates in the subgroup of children participating in serological allergy testing was also evaluated. The higher rates of reported symptoms in this subgroup were to be expected, but the development of prevalence rates over time was the same as in the larger sample.

To evaluate whether the time trend would be different in students with and without a family history of asthma and hay fever, separate analyses were run (table 4), but there was no significant increase in symptom rates in any of the subgroups.

Figure 1 displays the time trend in sensitisations rates for the small sample of Grabs students surveyed between 1983 and 2002 and the corresponding rates for the SCARPOL students examined between 1992 and 2000, excluding the students from Grabs. Sensitisation rates clearly increased between 1983 and 1993 but level off thereafter. Thus, the SCARPOL surveillance programme was started when the sensitisation rates had just begun to plateau.

Table 4.-Adjusted prevalence of asthma and rhinitis symptoms (parental reports) in three consecutive surveys, stratified by family history of asthma or hay fever

\begin{tabular}{|c|c|c|c|c|}
\hline Study sample/health outcome & $1992-1993$ & 1995-1997 & 1999-2000 & $\mathrm{p}$-value for trend \\
\hline Positive family history of asthma or hay fever $n$ & 432 & 602 & 494 & \\
\hline Wheeze ever & $33.2(27.8-39.1)$ & $32.9(28.1-38.0)$ & $33.7(30.4-41.2)$ & 0.52 \\
\hline Wheeze past year & $9.9(6.7-14.1)$ & $9.7(7.1-13.1)$ & $5.0(3.2-7.6)$ & 0.02 \\
\hline Wheeze after exercise & $9.9(7.0-13.8)$ & $10.4(7.8-13.8)$ & $9.4(6.7-13.1)$ & 0.80 \\
\hline Asthma ever & $15.8(11.9-20.6)$ & $16.5(12.9-20.7)$ & $12.0(8.9-15.8)$ & 0.15 \\
\hline Sneezing attack without cold and itchy watery eyes last year & $21.2(16.8-26.3)$ & $19.8(16.0-24.1)$ & $23.4(18.9-28.4)$ & 0.26 \\
\hline Hay fever & $31.0(25.8-36.5)$ & $30.6(26.1-35.5)$ & $32.0(27.0-37.3)$ & 0.88 \\
\hline Negative family history of asthma or hay fever $n$ & 892 & 1066 & 756 & \\
\hline Wheeze ever & $15.6(13.2-18.2)$ & $15.4(13.2-17.7)$ & $18.8(16.0-21.8)$ & 0.13 \\
\hline Wheeze past year & $3.4(2.4-4.8)$ & $3.4(2.5-4.7)$ & $3.9(2.7-5.5)$ & 0.58 \\
\hline Wheeze after exercise & $6.9(5.4-8.8)$ & $5.6(4.4-7.1)$ & $6.8(5.1-8.8)$ & 0.92 \\
\hline Asthma ever & $5.6(4.3-7.4)$ & $5.6(4.3-7.1)$ & $6.6(5.1-8.7)$ & 0.37 \\
\hline Sneezing attack without cold and itchy watery eyes last year & $10.6(8.7-12.9)$ & $7.6(6.2-9.4)$ & $7.9(6.1-10.0)$ & 0.06 \\
\hline Hay fever & $12.4(10.3-14.7)$ & $9.6(7.9-11.4)$ & $12.2(10.0-14.7)$ & 0.94 \\
\hline
\end{tabular}

Data are presented as \% (95\% confidence interval) unless otherwise stated. Symptom rates were adjusted for study year, sex, parental education, study area, breastfeeding, number of siblings, heating system, carpets in student's bedroom, pet ownership, getting rid of carpets because of the child's allergy, students active smoking, mother filling in the questionnaire and parental perception of air pollution as a risk factor for their child's respiratory health. 


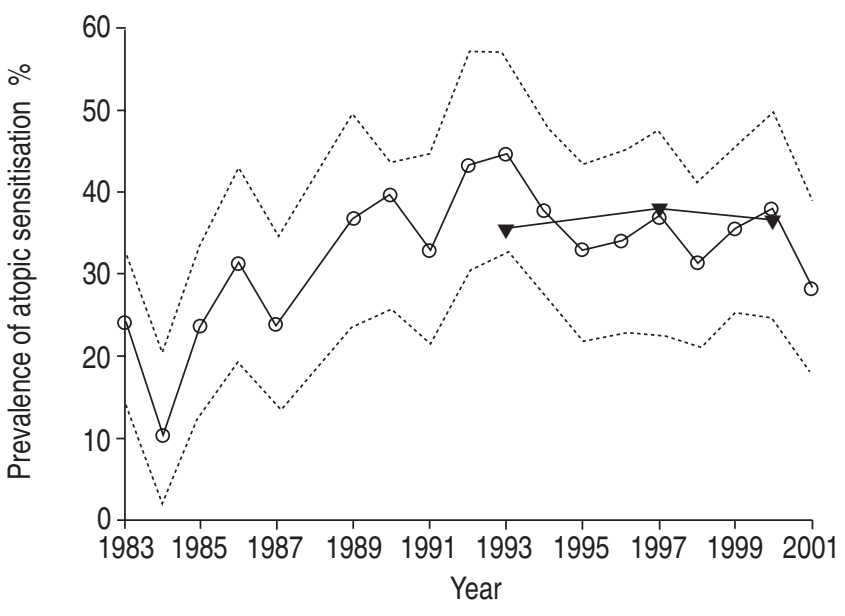

Fig. 1.- Prevalence of atopic sensitisation in adolescents from one study area (Grabs) and from the Swiss Study on Childhood Allergy and Respiratory symptoms with respect to Air Pollution (SCARPOL) sample excluding the students from Grabs versus the study year. $\bigcirc$ : Grabs; $\boldsymbol{\nabla}$ : SCARPOL; ……. $95 \%$ confidence interval.

\section{Discussion}

Among Swiss adolescents examined in three consecutive surveys in 1992-1993, 1995-1997 and in 1999-2000 the prevalence rates of asthma and current asthmatic symptoms remained constant, irrespective of whether the assessment was based on parental questionnaires or the student's selfcompleted written or video questionnaires. In addition, no further increase was observed for reported hay fever rates and allergic sensitisation rates determined by specific IgE measurements in the adolescent's sera. Although time trends in the occurrence of a series of known risk factors, such as parental education, parental asthma and hay fever, breastfeeding, number of siblings or pet keeping, were recorded, the inclusion of these factors into the multivariate analyses did not change the time trend of asthma and allergy prevalence. Sensitisation rates monitored in one of the study centres since 1983 [21] showed a clear upward trend until 1993, levelling off thereafter. The time trend in sensitisation rates in Grabs was paralleled by a similar change in hay fever prevalence [21]. These results support the notion that the increase in the occurrence of asthma and allergy among adolescents living in Switzerland might have come to an end.

The SCARPOL results are supported by the data of the Swiss Sentinel Surveillance Network, which records case notifications of asthma by primary healthcare providers since 1988 using a standardised disease definition. Until 1994 asthma consultations in primary care increased significantly and levelled off thereafter [23]. Similarly in England, when age-specific weekly rates of new episodes of asthma presenting to the general practitioners over 1989-1998 were analysed, increasing episode rates were observed between 1989 and 1993, which gradually decreased after 1993 [24]. The patterns of increase followed by reduction since 1993 or 1994 were evident in all age groups. However, it has to be recognised that general practitioner asthma consultation data may not only reflect an underlying time trend, but are also influenced by better management of asthma and increased use of corticosteroids. Interestingly, the observed pattern resembles the time trend seen in the present study for atopic sensitisation rates and hay fever prevalence rates in adolescents of the community of Grabs [21]. An earlier questionnaire-based study of Italian children aged 6-13 yrs surveyed in 1974, 1992 and 1998 found results similar to the ones of the present study; the prevalence of physician diagnosed asthma and parent reported attacks of breathlessness and audible wheezing during the past year had increased from 1974-1992 and remained stable until 1998 [11]. Similarly, a questionnaire survey in Ankara, Turkey, investigating primary schoolchildren in 1992 and 1995 using identical methods indicated that the prevalence rates of allergic diseases had stabilised during this 5-yr period [25]. Using routinely collected data from the National Centre for Health Statistics, AKINBAMI and SCHOENDORF [26] reported recently that asthma prevalence rates in children in the USA had significantly increased from 1980-1996, but had plateaued from 1997-2000. Thus, there exist now several studies that support the notion that the rate of increase may be tailing off. However, the SCARPOL study is the first to confirm this trend with objective data of atopic sensitisation.

In contrast to these studies giving evidence of a stabilisation of childhood asthma and allergy rates during the 1990s, two repeated cross-sectional studies reported increasing asthma and atopy prevalence during the same time period. In Australia [13], sensitisation rates measured by skin-prick test increased from $38.7 \%$ in 1992 to $45.4 \%$ in 1997 and were paralleled by an increase in asthma symptoms and medication use but not in hay fever and nasal allergies. A questionnaire survey in preschoolchildren from Leister, UK, assessing wheezing disorders in 1990 and in 1998 found a doubling in reported prevalence of wheeze, doctor diagnosed asthma, and healthcare use, which was not explained by over-reporting of mild symptoms or diagnostic transfer [12]. However, public awareness bias cannot be completely ruled out in a pure questionnaire survey.

The present study also attempted to monitor time trends of risk factors that had been associated with asthma and allergy in the past. Although several of these factors were significantly associated with asthma or hay fever symptoms in crosssectional analyses, few of them changed over time and none had a significant impact on time trend when adjusted for, in multivariate analyses. As the adjusted prevalence rates represent the net effect of all risk factors positively or negatively associated with health outcome, the authors evaluated whether the change in a single exposure factor over time would have had an influence on the time trend if all other influential factors had stayed the same. However, the influence of any of the risk factors on time trend was minimal, the strongest being parental history of hay fever, which increased the reported hay fever prevalence of the student by $0.5 \%$. Yet, potentially influencing factors, such as dietary habits [17] or body mass index [27] have not been assessed in the present study. However, it has been recently shown that trends in overweight and obesity did not explain the increase in asthma in British children between 1982 and 1994 [28]. In previous analyses of the first SCARPOL crosssectional study in 1992-1993 long-term exposure to ambient air pollution has not been associated with asthma or allergy prevalence [18]. Adjustment for changes in air pollution levels between 1992 and 1999 in the present analyses did not influence time trends of asthma and allergy rates as well.

A limitation of the present study is the relative low participation rate for the blood sampling associated with a tendency of those participating to come from atopic families. Consequently, the symptom prevalence in this selected sample was higher than in the total sample. However, as the same selection mechanism was operating in all three surveys, it is unlikely that this selection process may have biased the time trend in reported symptoms and sensitisation rates. In addition, the same time trends were observed in the subsample of adolescents from Grabs where participation rates for blood sampling were $>75 \%$. A further methodological constraint is the moderate-to-low agreement between parental and 
students' reports of symptoms prevalence as previously reported $[29,30]$. Students' reported rates of current wheeze differed considerably between the written and the video questionnaire. This is likely due to the fact that the video scene displays a rather severe form of wheeze and the students reported whether they had experience the symptom shown in the video. Yet, as there was no change in the kappa statistics between the three surveys, the limited agreement between the different questionnaire responses is not likely to bias the results. It has further to be recognised that the time period of $8 \mathrm{yrs}$ is too short to definitively assess a time trend.

Hay fever rates among the parents of the SCARPOL children were still on the rise suggesting a cohort effect, i.e. an increase among subjects born in the fifties as has been reported by others $[31,32]$. The results from the current study suggest that the rising trend in allergic sensitisation has come to an end among cohorts born in the late seventies and eighties. An appealing interpretation to the observed stabilisation in the prevalence of asthma and allergy is that the maximal genetic potential for a gene by environment interaction underlying the development of the disease has been reached. However, this is purely speculative, as the genetic potential for asthma and atopy of a given population is unknown and data from Australia indicate that higher sensitisation rates than those in Switzerland may be reached [13]. Alternatively, it may be hypothesised that exposure to environmental factors, summarised as "Western lifestyle", intensified predominantly during the fifties and sixties and remained fairly constant during more recent years, thus no longer influencing the time trend of asthma and allergies in cohorts born in the eighties. Data from the current study do not allow the difference between the two explanations to be clearly distinguished.

In conclusion, the results of these three consecutive surveys in adolescents living in Switzerland assessing time trends in asthma and allergy including an objective marker of atopy suggest that the increase in prevalence in this age-group may have come to an end. However, to definitely assess a time trend a longer period of observation is needed.

\begin{abstract}
Acknowledgements. The authors are grateful to their many colleagues in the School Health Services who organised the survey. They would also like to thank the children, parents and teachers for their enthusiastic cooperation, which made this investigation possible, and the laboratory staff of the Allergy Unit of the Dept of Dermatology, University Hospital of Zurich for careful performance of the specific immunoglobulin $\mathrm{E}$ measurements. The authors very much appreciated the statistical advice of C. Schindler, Institute of Social and Preventive Medicine, University of Basel.
\end{abstract}

\section{References}

1. Burr ML, Butland BK, King S, Vaughan-Williams E. Changes in asthma prevalence: two surveys 15 years apart. Arch Dis Child 1989; 64: 1452-1456.

2. Ninan TK, Russell G. Respiratory symptoms and atopy in Aberdeen schoolchildren: evidence from two surveys 25 years apart. BMJ 1992; 304: 873-875.

3. Peat JK, van den Berg RH, Green WF, Mellis CM, Leeder SR, Woolcock AJ. Changing prevalence of asthma in Australian children. BMJ 1994; 308: 1591-1596.

4. Varonier HS, de Haller J, Schopfer C. Prevalence of allergies in children and adolescents [Prévalence de l'allergie chez les enfants et les adolescents]. Helv Paediatr Acta 1984; 39: 129136.

5. Magnus P, Jaakkola JJ. Secular trend in the occurrence of asthma among children and young adults: critical appraisal of repeated cross sectional surveys. BMJ 1997; 314: 17951799.

6. Burney P. The changing prevalence of asthma. Thorax 2002; 57: Suppl. 2, 36-39.

7. Rona RJ, Chinn S, Burney PG. Trends in the prevalence of asthma in Scottish and English primary school children 1982-92. Thorax 1995; 50: 992-993.

8. Aberg N, Hesselmar B, Aberg B, Eriksson B. Increase of asthma, allergic rhinitis and eczema in Swedish schoolchildren between 1979 and 1991 (see comments). Clin Exp Allergy 1995; 25: 815-819.

9. Wüthrich B, Schindler C, Leuenberger P, AckermannLiebrich U. Prevalence of atopy and pollinosis in the adult population of Switzerland (SAPALDIA study). Int Arch Allergy Immunol 1995; 106: 149-156.

10. Gassner M, Kurtz M, Wüthrich B. Prevalence of pollinosis in schoolchildren [Zur Prävalenz der Pollinosis bei Schulkinder]. Allergologie 1996; 19: 403-408.

11. Ronchetti R, Villa MP, Barreto M, et al. Is the increase in childhood asthma coming to an end? Findings from three surveys of schoolchildren in Rome, Italy. Eur Respir J 2001; 17: 881-886.

12. Kuehni CE, Davis A, Brooke AM, Silverman M. Are all wheezing disorders in very young (preschool) children increasing in prevalence? Lancet 2001; 357: 1821-1825.

13. Downs SH, Marks GB, Sporik R, Belosouva EG, Car NG, Peat JK. Continued increase in the prevalence of asthma and atopy. Arch Dis Child 2001; 84: 20-23.

14. Strachan DP, Cook DG. Health effects of passive smoking. 6. Parental smoking and childhood asthma: longitudinal and case-control studies. Thorax 1998; 53: 204-212.

15. D'Amato G, Liccardi G, D'Amato M. Environmental risk factors (outdoor air pollution and climatic changes) and increased trend of respiratory allergy. J Investig Allergol Clin Immunol 2000; 10: 123-128.

16. von Mutius E. Pro: the increase in asthma can be ascribed to cleanliness. Am J Respir Crit Care Med 2001; 164: 11061107; discussion 1108-1109.

17. Black PN, Sharpe S. Dietary fat and asthma: is there a connection? Eur Respir J 1997; 10: 6-12.

18. Braun-Fahrländer C, Vuille JC, Sennhauser FH, et al. Respiratory health and long-term exposure to air pollutants in Swiss schoolchildren. SCARPOL Team. Am J Respir Crit Care Med 1997; 155: 1042-1049.

19. Asher MI, Keil U, Anderson HR, et al. International Study of Asthma and Allergies in Childhood (ISAAC): rationale and methods. Eur Respir J 1995; 8: 483-491.

20. Pastorello EA, Incorvaia C, Pravettoni V, Marelli A, Farioli L, Ghezzi M. Clinical evaluation of CAP System and RAST in the measurement of specific IgE. Allergy 1992; 47: 463-466.

21. Gassner-Bachmann M, Wüthrich B. Farmers' children suffer less from hay fever and asthma [Bauernkinder leiden seltener an Heuschnupfen und Asthma]. Dtsch Med Wschr 2000; 125: 924-931.

22. Nelder JA, Weddenburn RW. Generalized Linear Models. J R Stat Soc 1972; 135: 370-384.

23. Bollag U, Cloetta J, Oberreich J, Paget W. Asthma trends in Switzerland: reports by primary care physicians in the Swiss Sentinel Surveillance Network between 1988 and 1996. Euro Surveill 1999; 4: 21-24.

24. Fleming DM, Sunderland R, Cross KW, Ross AM. Declining incidence of episodes of asthma: a study of trends in new episodes presenting to general practitioners in the period 1989-98. Thorax 2000; 55: 657-661.

25. Kalyoncu AF, Selcuk ZT, Enunlu T, et al. Prevalence of asthma and allergic diseases in primary school children in Ankara, Turkey: two cross-sectional studies, five years apart. Pediatr Allergy Immunol 1999; 10: 261-265. 
26. Akinbami LJ, Schoendorf KC. Trends in childhood asthma: prevalence, health care utilization, and mortality. Pediatrics 2002; 110: 315-322.

27. Shaheen SO, Sterne JA, Montgomery SM, Azima H. Birth weight, body mass index and asthma in young adults. Thorax 1999; 54: 396-402.

28. Chinn S, Rona RJ. Can the increase in body mass index explain the rising trend in asthma in children? Thorax 2001; 56: 845-850.

29. Pizzichini MM, Rennie D, Senthilselvan A, Taylor B, Habbick BF, Sears MR. Limited agreement between written and video asthma symptom questionnaires. Pediatr Pulmonol 2000; 30: 307-312.
30. Braun-Fahrländer C, Gassner M, Grize L, et al. Comparison of responses to an asthma symptom questionnaire (ISAAC core questions) completed by adolescents and their parents. Pediatr Pulmonol 1998; 25: 159-166.

31. Leynaert B, Neukirch C, Jarvis D, Chinn S, Burney P, Neukirch F. Does living on a farm during childhood protect against asthma, allergic rhinitis, and atopy in adulthood? $\mathrm{Am}$ J Respir Crit Care Med 2001; 164: 1829-1834.

32. Linneberg A, Nielsen NH, Madsen F, Frolund L, Dirksen A, Jorgensen $\mathrm{T}$. Increasing prevalence of specific $\mathrm{IgE}$ to aeroallergens in an adult population: two cross-sectional surveys 8 years apart: the Copenhagen Allergy Study. J Allergy Clin Immunol 2000; 106: 247-252. 